\title{
News, Trends, and Comments
}

\section{NEWS}

\section{Use acid-free paper}

A statement dated March 15th 1991, adopted by the working group of European Librarians and Publishers (ELP), has been circulated recently by the International Group of Scientific, Technical \& Medical Publishers (STM). The statement says that "Books and serials are endangered by the use of acid-containing paper... publishers and librarians, therefore, must urge a widespread use of permanent paper in order to safeguard the printed word as part of the cultural heritage for future generations".

This applies to all materials in all component parts of a publication. Permanent paper should be $100 \%$ bleached cellulose without mechanical pulp fibres (without lignin) with a calcium carbonate buffer of at least $2 \%-3 \%$, and a $\mathrm{pH}$ value of $7.5-9$ ( 7 is neutral).

The paper should conform to European standards and should be marked with the infinity sign. ELP asks for government and CEC support for further research and standardisation.

\section{Elsevier's hit list}

According to the UK Daily Telegraph, Elsevier maintains "inside its Amsterdam headquarters a monthly hit list of worldwide targets ranging from the possible - such as the Jovanovich titles - to the unlikely, including United Newspapers, publishers of the Daily Express. Elsevier's 1990 profits were substantially up on 1989 maintaining its 20 year growth rate at an average of $20 \%$ per annum.

In 1990 Elsevier held merger talks with VNU but agreement was not reached. During the first four months of 1991, Elsevier's name has appeared frequently in the financial columns. In early March, Pearson sold its $22.5 \%$ holding in Elsevier for about $£ 313 \mathrm{M}-£ 84 \mathrm{M}$ more than it paid two years ago due a rise in the guilder and in the price of Elsevier's shares. This ends the possibility of a merger.

In April Elsevier sold its $8.8 \%$ holding in Pearson for a loss of about $5 \%$ In the same month it bought Pergamon Press for $\$ 440 \mathrm{M}$ cash. Pergamon publishes over 500 scientific journals, adding to Elsevier's present total of about 650, making it easily the world's largest scientific journal publisher.

\section{Aslib activities}

Aslib - once the Association of Special Libraries, now the Association for Information Management - found itself in a loss-making situation in 1989. It appointed a new Chief Executive, Roger Bowes, and moved to premises in Old Street, London. It is hoping for better things in 1991 and continues to be very active in the information world. 
Together with the Institute of Translators and Interpretors it is organising a conference at the CBI Conference Centre, London, on 28th29th November, 1991, entitled "Translating and the Computer 13" (the 13th in the series). Session titles are "Setting the Scene in Translation, Multinational Character Sets, Terminology, Quality and Testing, MT at Work and The Future of Translating".

Aslib has expanded its consultancy business and provides services with its own staff and from a pool of external consultants. It offers a fixed price service called ASSESS, providing an "information management audit" to "judge either the general fitness of a library or information services" providing a general assessment and suggestions for improvement.

Aslib published the first issue of a glossy monthly magazine "The Intelligent Enterprise" in March 1991. Priced at $£ 90$ per year ( $\$ 75$ to members) it will focus on all aspects of business intelligence gathering and use. The leading article in the first issue discusses Venture Capital in the $\mathrm{UK}$ and includes other bright and breezy articles and news items.

\section{DIALOG news}

DIALOG has opened a Swiss office at Neuchatel (+41 (0)38 205639). 25 DIALOG products are now available on CD-ROMs for running on any make of drive with Microsoft Extensions 2.0 or higher driven by a PC XT, AT, or PS/2.

The products include Compendex, Metadex, NTIS, Medline, ERIC, and many others. DIALOG can now also supply software so that its CD-ROMS may be run on Apple Mac machines.

\section{DIALTECH}

The British Library took over the UK national centre for ESA-IRS on April 1st 1991. It will be a self-supporting operation within BL's science reference and information services, previously funded by the Department of Trade and Industry.

\section{BRS news}

BRS now offers a low cost "morning search" search service for its European customers with connect hour charges reduced by up to $60 \%$ and citation charges by up to 50\%. These rates apply in the UK for 14 hours between 2300 and 1300 hours, UK time.

A new European telecoms service is to be introduced with direct local dialling and a simple logon procedure without NUI or NUA. The connect time will be $\$ 10$ per hour.

\section{ISI news}

Commencing March 1991 ISI added abstracts to its online Scisearch and Current Contents Search databases. Abstracts are included for all scientific articles covered where the author has supplied an English language abstract - about $75 \%$ of the articles. 
Scisearch covers over 4400 scientific and technical journals consisting of about 31,500 journal issues with 655,000 articles each year. CC provides access to these journals plus 1300 social science journals and 1200 arts and humanities journals with 45,000 issues and about 950,000 articles.

\section{ADONIS}

The most recent issue of new-style ADONIS News (2(1), May 1991) says that the most important recent technical improvement is in optimizing printing speed. It also says that a US-based support facility is being considered, that networking and jukebox support is being developed, and that support for other operating systems may soon be introduced. ADONIS is in full production. The News includes a list of the large number of journals covered on the CD-ROM which is re-issued about once weekly.

It was hoped that compression would enable 15,000 pages to be included per CD but at the compression ratio needed laser print quality was unsatisfactory. At 10,000 pages per CD, print quality is said to be excellent.

Findings at a recent presentation in the US to drug companies were:- "the royalty payments to Copyright Clearance Centre and ADONIS are perceived to be a threshold for the US pharmaceutical industry to commit themselves... networking the library is perceived to be crucial for information management".

\section{ORBIS 91 Business Information Meeting}

Learned Information, Oxford, and Cerved, the Italian economic information provider, announce the second ORBIS conference and exhibition to be held in Rome at the Sheraton Centre from September 30th to October 3rd 1991.

"ORBIS 91 is based on the conviction that the diffusion and distribution of economic information is one of the most efficient ways for companies to take advantage of the ever-increasing and interlinking opportunities on the market today".

\section{LA Conference - Library and Information Studies in Europe}

The Library Association (+44 (0)71636 7543) is arranging a six day seminar at its London Headquarters on March 26th-31st, 1992, entitled "Library and Information Studies in Europe". It is "designed to bring together key staff teaching Library and Information Studies to consider developments and share plans". Speakers include Professor Guy Neave (Paris), Professor Tom Wilson (Sheffield), and Professor Peter Vodosek (Stuttgart).

\section{CD-ROM roundup}

Cuadra Elsevier (+1 213477 1078) announce a CD-ROM of the Cuadra Directory of Databases on Disc covering over 4700 online and 1500 portable 
databases. Each CD-ROM contains information retrieval software. Online databases out-numbered portables by 7 to 1 a year ago; now the figure is 3 to 1.

Lotus One Source (+1 8005545501$)$ offer a series of business CDROMs "CD Corporate", "CD Banking" and "CD Investment". Corporate lists details of US and UK public and private companies plus information about $10,000 \mathrm{UK}$ and European mergers and acquisitions. Banking covers 14,000 US banks together with data about holding companies, savings \& loans, saving banks, and branches. Investment provides extensive information about US companies, stocks, and financial issues.

A unique feature of these CD-ROMs is that the data can be integrated with Lotus 1-2-3 spreadsheets so that data from the CDs may be specified, processed and retrieved from a spreadsheet according to a user's analytic requirements.

Microinfo's (+44 (0)420 89889) World Research Database, priced at $£ 1600$ contains details of 20,000 research centres and a who's who of nearly 50,000 senior scientists and technologists providing "opportunities to use the database for reference purposes or printing out names and addresses for mailing purposes". Microinfo are also adding Longman's World Energy $\mathrm{CD}-\mathrm{ROM}$ to their distribution list.

Grolier's (+1 203797 3500) Academic American Encyclopaedia is now available for Apple Macs. There is a rather involved story about making it work in Byte, October 1990, pps 92-95. The reviewer's conclusion is that "The pictures and articles are excellent. This would be a better product if the company adopted less paranoid policies". He is referring to problems with the software but says "I understand that they are reconsidering".

Bowker-Saur (+ $44(0) 732884530)$ list some $18 \mathrm{CD}$-ROM products in their current catalogue. They include several new products. SciTech Reference Plus covers 130,000 scitech books, 18,000 scitech serials, 125,000 US and Canadian scientists \& engineers, 11,000 R\&D laboratories, and 30,000 leading US technology firms.

Library Reference Plus covers "Every conceivable fact, statistic, contact name, address, activity and support service relating to the library, publishing and book-trade in the US".

Music Directory Plus can "answer questions posed about the tens of thousands of recordings in active distribution today", and Enviro/Energyline Abstracts includes the backfile and current files from Environmental Abstracts, Energy Information Abstracts, and Acid Rain Abstracts.

Goupil Drive. Goupil (+ 33143996000 ) can supply a Hitachi 6300 CDROM drive, called Golf, modified so that it takes a 40 Mbyte hard-disk drive, 1.44 Mbyte floppy, up to 9 Mbytes of RAM and a half-size expansion slot. It still only weighs 22 pounds but costs $\$ 9900$.

Pioneer Jukebox (+1 2135131016$)$, priced at $\$ 1495$, is described in Jerry Pournelle's "Jukebox computing" (Byte, January 1991, pps 73-80). The Pioneer DRM-600 CD-ROM drive holds six compact discs and can be used as both a CD audio player connected to a Hi-Fi outfit or as a CD-ROM player. 


\section{Online roundup}

UMI/Data Courier (+1 8006262823 ) announced several improvements to its products in May 1991. Full text articles from about 100 major business publications have been added to its ABI/INFORM database. ABI/INFORM itself has been re-loaded with numerous additions and revisions, 80 new publications have been added, and the number of records added weekly has been increased to about 1200 .

Dialog file 484 has been re-named "Newspaper and Periodical Abstracts". It contains more than 1.5 million citations to articles in the most important newspapers and journals. Journal coverage will be doubled in 1991, the database will be up-dated daily, and five major newspapers will be up-dated within 48 hours of publication.

ECHO, the EC organization, ( +352488041$)$ provides free access to a database called Eurodicautom which contains scientific and technical terms, contextual phrases and abbreviations, in all the official EC languages. The database provides translations of 420,000 terms and 120,000 abbreviations, up-dated with about 2000 terms monthly. Freephone telephone access numbers are available in seven different countries.

Thomson \& Thomson (+1 617479 1600) have added "TrademarkscanUK" to its other trademark databases. It contains information on all actively registered trademarks and applications for registration filed with the UK Patent Office.

Pergamon Financial Data Service's (+44 (0)71 490 0049) June 1991 catalogue lists over 50 databases for marketing \& sales analyses, financial intelligence, business intelligence and chemical industry information.

The databases include BSI Standards, DIN German Standards, ESA/IRS, Hoppenstedt, Jordanwatch, Official Airlines Guide, PIRA, RAPRA etc.

\section{TRENDS AND COMMENTS}

\section{Aftermath of "Competition and Choice" for UK Telecoms}

The US led in telecommunications deregulation. The balance of opinion seems to be that present arrangements in that country are an improvement, but there are many dissenters. The UK version was to set up a "duopoly" - British Telecom with a single competitor, Mercury. The net result was insufficient competition. Even so, Mercury is doing quite well. Owned by Cable \& Wireless, in June 1991 it announced profits up $75 \%$ to $1116 \mathrm{M}$. It undercuts BT by about $19 \%$ on average. BT's annual profits are running at about $£ 3.5$ Billion.

Following various curtain-raisers, including an idea to build a $£ 20$ billion national wideband fibreoptic network, UK government proposals were put forward in a November 1990 "Green Paper" entitled "Competition and choice: telecommunications policy for the 1990s". In March 1991 this was followed by a White Paper affirming most of the proposals.

The most important feature which, it is hoped, will provide real competition, is the permission to be given to Cable franchise operators to 
interconnect between themselves and to provide telephone service inclusive of the "local loop" into households and businesses. A major advantage is that subscribers will then be provided with the potential benefit of a wideband "information services" connection. Secondly, private networks may be created with a connection to the PSTN.

The basic problem in the aftermath of the White Paper is that the government wants to maximise the $₹$ Billions revenue from the sale of its $49 \%$ holding in BT, later this year. It also (presumably) wants to implement its White Paper policy to enable others to compete. To do that it must be possible for competitors to connect to subscribers via the BT-owned local loop. Even the cable companies will not be able to provide anything like a fully competitive service for years unless they can interconnect with BT.

$\mathrm{BT}$, of course, is not going to encourage competition by offering cheap interconnections. Unless OFTEL, the UK regulatory office, leans on BT to make its connection charges "reasonable", competitors will not be encouraged - but what is "reasonable"? Until it has sold its shares, the government is unlikely to jeopardise the worth of its investment by leaning on OFTEL to do something.

\section{European Court backs EC}

Last year the EC was disuaded by a court advocate from invoking Article 90 of the Treaty of Rome to support its directive to the European PTT's to purchase terminals on the open market. The ruling had been opposed by France. The usual procedure was to buy from the home market. Although the matter has been overtaken by events - terminal liberalisation has, in fact, taken place - the European Court of Justice has belatedly found in favour of the EC action.

The importance of the ruling lies in the establishment of a precedent which the EC will probably use to force through other measures leading to improved European-wide communications which are being slowed up by recalcitrant PTTs.

\section{LEO Reminiscences}

National pride being what it is, claims to the invention of the first computer are numerous. Quite a few hinge on the definition of a computer. Babbage's projected machine of the 1830 s - currently being reconstructed at the Science Museum, London, mainly out of turned brass parts to see if it could have worked - was a kind of computer. Babbage's collaborator, Lord Byron's daughter Ada (Lady Lovelace) has been called "the world's first programmer.

The best claims to the title of the world's first electronic computer seem to lie with ENIAC or COLOSSUS. ENIAC was built at Princeton University in 1945 by John von Neumann, J.Presper Eckert and John W. Mauchly and has been much discussed. COLOSSUS was started in February 1943 at the Post Office Research Station, Dollis Hill, London, and completed the following January. Subsequently it was moved to Bletchley Park and several were made for deciphering messages encyphered by German ENIGMA 
machines. Since, to this day, it is clothed with obsessive British secrecy, its claims to fame are overdue.

COLOSSUS contained 2000 valves and used a loop of 5-hole punched paper tape as input. The construction team was led by Tommy Flowers and included Max Newman, "Doc" Coombs and Sydney Broadhurst.

The first machine to enter regular commercial service with a microprogramming system - and here I stand to be corrected - was probably LEO, started in 1949 by J.Lyons \& Co., in West London. It was used for payroll work and has been described recently by J.M.M.Pinkerton (IEE Rev. January 1991, 13-17) who worked on it. It was based on a machine called EDSAC built at Cambridge.

It used a paper tape reader. Pinkerton was an expert in ultrasonic wave propagation in liquids - a necessary qualification because LEO's memory was made out of mercury-filled delay lines capable of storing 2048 17-bit words. $150 \mathrm{LEO} 3 \mathrm{~s}$, an improved version which used transistors and magnetic core storage, were built.

A major problem with early models was the reliability of the 5000 valves (tubes) which LEO contained. All kinds of precautions were taken like regular testing of each valve, slow warm-up of the heaters before applying the HT voltage and special pre-operational testing which lasted up to one hour. The result was a mean time between failures of around 10 hours.

\section{ESPRIT}

ESPRIT - the European Strategic Programme for Research and Development in Information Technology - was launched in 1984. It supports companies with up to $50 \%$ of the costs of approved research projects, and universities and research centres with up to $100 \%$.

In 1989, 292 large companies, 386 small and medium-sized (up to 500 employees) companies, 184 universities and 109 research and other institutes were involved (ESPRIT 1989 Annual Report, Office for Official Publications of the CEC, Luxembourg. 1990.)

The projects of most interest to readers of this journal are classified under "Information Processing Systems" or "Office \& Business Systems".

Here are some examples, showing participants in each project, with comments from the report, by way of illustrating the diversity:-

28. MULTOS. A multimedia filing system.

Batelle, CNR, Cretan Computer Inst., C.Eria, Olivetti, Mnemonica, Philips, Triumph-Adler.

"The power of MULTOS has been illustrated in a demonstration based on documents used by the El Pais newspaper containing text and images, showing documents being brought into the system through a scanner, manual and automatic classification, filing and retrieval".

2589. SAM. Multi-lingual speech input/output assessment and standards. University College, AEG, CRIN/ADILOR, CSELT, Elab, Jysk Telefon, Televerket, TNO.

"SAM will play a central role within the speech processing community 
by providing standard techniques for assessing the quality of both synthesisers and recognizers in eight different languages".

121. HERODE. Handling of mixed text/image/voice documents based on standardized office document architecture.

CRIN/ADILOR, Siemens, TITN.

"This work has supported the development of ODA (Office Document Architecture) and ODIF (Office Document Interchange Format) standards which have now been adopted by many European companies".

PICA. A high compression photo-videotex picture coding algorithm. Brit. Telecom, CLETT, CSELT, Indep. Broadcast Auth., KTAS, Nixdorf, PTT Nederland.

"PICA set itself a target of a 16:1 compression ratio. This it far exceeded offering ratios of at least 20:1 and as much as 192:1 where lower quality is acceptable. The algorithm is now a world standard embodied in ICs produced by the participating companies. It was used for transmitting colour photographs via $\mathrm{HF}$ radio from yachts taking part in the 1990 Whitbread Round the World yacht race".

169. LION. Local Integrated Optical Network.

Brit. Telecom, CSELT, Nordiske KAbel, Politechnico di Milano, TITN, Univ. Paris, Univ. Toulouse.

"LION has demonstrated all the elements of a $140 \mathrm{Mb} / \mathrm{s}$ LAN and the possibility of speed increases up to $565 \mathrm{Mb} / \mathrm{s}$. LION has been the first to tackle some of the technical issues involved in the highbandwidth multimedia communication and is in many respects technically the best approach developed so far".

295. THE PAPER INTERFACE.

AEG Olympia, Olivetti, Philips, Plessey, Trent Poly.

"The project explored the whole gamut of document reading technologies. From it emerged a number of commercially exploitable elements. AEG uses recognition algorithms... as part of a letter sorting system... and were awarded a $\$ 300 \mathrm{M}$ contract from US Mail".

Two related schemes have since been agreed - RACE II (Research and Technological Development Programme in the field of Communication Technologies) covering the period 1990-1994, supported with 484M Ecu (10 Ecus $=£ 7=\$ 11.5$ approx) and "Research and Technological Development Programme in the field of Telematic Systems of General Interest" supported with $376 \mathrm{M}$ Ecu. No acronym has been provided for this mouthful - obviously "RATS" would be unacceptable. The deadline for proposals was 16th September 1991. The priority areas for RACE II and Telematic Systems are:-

Integrated Broadband Communications (IBC).

Intelligent networks; communications resource management.

Mobile and personal communications.

Image and data communications.

Integrated services technology.

Information security technologies.

Advanced communication experiments.

Test infrastructures and interworking to support other areas. 
Trans-European network administration.

Road transport telematics.

Health care telematics.

Flexible and distance learning.

Library services.

Linguistics

Rural areas.

See also the book by Hardy, reviewed below.

\section{BOOKS}

Simpson, I.S.

How to interpret statistical data: a guide for librarians and information scientists.

Library Association Publishing. London. 1990.

ISBN 0-85365-729-7. 78 pages.

A very useful little book covering the representation, presentation, and manipulation of data with numerous figures and examples using library data. A bibliography and index are included.

However I am not sure that some of the numerous examples of the behaviour of humans in libraries are solvable by calculations based on random sampling as is suggested. For instance an example of applying the Poisson distribution is given:- "Out of a random sample of 400 books returned to a library, only 20 are overdue. If a reader is allowed to borrow a large number of books what is the probability that, when returning 40 books, there will be none overdue - or one, or two, or three?

Say the sampling is done when the avid readers from local colleges, representing $25 \%$ of all borrowers, but who tend to hang on to books, are on vacation? Today they are back, so what are the overdue probabilities in today's returns?

Anon.

The information business: issues for the 1990s.

HERTIS, Hatfield Polytechnic, Hatfield, Herts, England. 1991. ISBN 0-852672-98-5. 94 pages.

This book is the proceedings of a conference on charging for information which took place at Hatfield on July 18th, 1990. The 5 papers about the subject contain much of interest.

In an opening address, Richard Luce, Minister for the Arts, said:"my concern has been to preserve the principle of free access of information in its raw state while at the same time giving public libraries access to additional sources of revenue through the exploitation of the information they hold through value added services... we have moved on to where the question is no longer "fee" of "free", but where a service is to be charged for, how the fees are calculated". 
John Ackroyd, Head of Library Resources, South Bank Polytechnic, says:- "In my experience it is very unlikely that those in the public sector... will be able to make money by selling information. Profits and surpluses are far more likely to come from consultancies and similar dedicated information functions, than from routine enquiry-based services.

Hilary Whelan, formerly head of business intelligence at BP, explains that in the early 80 s, corporate funding was withdrawn from the company's Central Information \& Library Services (CILS), and CILS became a fully charged service available to BP worldwide. By 1989 it had 20 staff and its average annual turnover was about $11.7 \mathrm{M}$. "Traditionally", says Whelan, "in-house services have not been good at promoting themselves... when the unit's survival depends entirely on customers buying its services, promotion is absolutely essential".

"One of the advantages of charging out is that it becomes possible to create new services if customers are willing to pay for them. This makes a pleasant change from continually cutting back on services which users want but which some central authority is not prepared to fund".

Lorna Newman, Library Services Manager, Glaxo Group Research, says:- "We use contractors to enable services which are already under pressure to cope with heavy workloads or peaks of work... contractors are used to gain access to online services or printed material which it would not be cost-effective to hold within the company... we can release resources to undertake higher value activities, and, at the same time, improve the quality of the job which we able to offer to staff".

Philip Holmes, Managing Director Jor dans Group, describes the Public Library Development Incentive Scheme in which he and others are involved. Business information will be delivered via satellite to four public library locations. The libraries "have argued strongly that collaboration on the provision of a business information service involving sales, marketing, education, and training will be a key benefit from the project".

Hardy, P., Pesce, E., and Wiesner, A .

Making public administrations more efficient with integrated systems.

Elsevier Science Publishers. Amsterdam 1991. ISBN 0444890211.

293 pages.

This book is a guide produced as part of ASTRA, project 831 in ESPRIT (discussed earlier) - a four year project which started in 1986. It covers user's needs, strategies, methods, cost benefits, security, quality, software, choice, and purchase. It concludes with a good bibliography and index.

The following activities are included in a market overview of "functionalities":-

Public administration user needs.

Image document storage and retrieval.

Image document processing. 
Image document distribution control.

Document printing, scanning, etc.

Information flow control.

Individual data processing.

Forms processing.

Electronic Mail.

Complete adherence to CEC standards.

Connectivity.

Open system architecture.

In a table of 11 major systems, including Filenet, Megadoc, Dissoss, etc., only ASTRA provides all functions, but it is hardly surprising that only ASTRA includes the idealistic items "Complete adherence to CEC standards" and "Open system architecture".

ASTRA is an attempt to realise a dream which from time to time is claimed to be today's reality starting with Engelbart's NLS at Stanford, and continuing with numerous systems such as Ellis's OFFICETALK, Zisman's SCOOP, and Zoof's "Query by example". The dream is about information flow and system connectivity in big offices.

In ASTRA the realisation of the dream has come closer with the advent of optical storage; cheap processing power enables documents to be handled as digitized images. A rather dry view is taken of social aspects:- "... we recommend managers to conduct a study during the design phase to determine state of mind... to avoid conflicts or resistance... users must trust, agree, and then implement".

The book reflects the thoroughness of the investigation and should certainly be read by anybody contemplating large-scale office activities.

D'Souza, Frances (Director), Bedford, Carmel (Editor).

Information, Freedom and Censorship. Article 19 World Report.

Library Association Publishing. London. 1991.

ISBN 1-85604-021-6. 471 pages.

Taking its name from the 19th article of the Universal Declaration of Human Rights, Article 19 is an international centre on censorship. This extraordinary book acknowledges the assistance of about 60 people for research and compilation. It consists of articles about 77 different countries followed by 4 chapters on censorship themes and issues, a bibliography and an index.

Each country article includes an introduction to the country, a table of statistics - population, GNP, language, literacy, media, etc., a piece about the media and freedom of expression, and often a piece about special situations in the country, and attempts at remedial action.

"In 62 of the 77 countries people remain in detention for having peacefully expressed their opinions... In 27, people, including journalists, continue to be tortured or killed for their opinions, and extra-legal censorship operates in 72 countries including the US, the UK, and most of Western Europe. Highly informative but often cheerless reading. A unique reference book. 
Martyn, John, Vickers, Peter, and Feeney, Mary (Eds).

Information UK 2000.

Bowker Saur for British Library Research. London. 1990.

ISBN 0-86291-620-8. 293 pages.

This book is a forecasting exercise to "raise the level of awareness within the library and information community of the potential for change and innovation, to assist policy and decision making in the medium term, and to help in planning future research".

It originated as a proposal from Julian Blackwell for an investigation into new technology and scholarly publishing at a British National Bibliography Research Fund committee meeting on January 26th 1989. Subsequently the field was widened and in view of the enlarged scale, Brian Perry, director of British Library $R \& D$, offered to support it as an R\&D project.

11 task forces were established with a total of 58 members to cover Social trends, The technological imperative, Archives, libraries and information services, Recording and reproducing, Communications infrastructure, Publishing, new products, distribution and marketing, Individual and domestic use of information, Organizations and their use of information, Manpower, education, and training, Issues for information users and Issues of policy from the policy-maker's viewpoint.

It contains an overview, a chapter about each of the topics listed above, a chapter entitled "recommendations for future action" a glossary, and an index.

Papers from the task force members are available in sets from the British LIbrary Document Supply Centre, Boston Spa, as are papers by additional contributors as follows:-

A.E.Cawkell. Telecommunications futures: 2000 and beyond.

J.C.Grey. Survey of information policy in professional institutions; user forum.

Prof. R. Hayes American academic library developments. Dr. M. Lesk Trends in technology.

Prof. S.E. Robertson Developments in basic research.

C. Sweeten Likely developments in bookselling and library supply.

EPS Ltd. Survey of European developments.

It is difficult to single out parts of such a wide-ranging book for special mention. However such a major effort co-ordinated by the British Library is unlikely to go un-noticed, so I assume it will become a library best-seller and will be perused by most readers of this journal in due course wherever they reside; much of it is not UK-specific.

Comments can be conveniently confined to the overview chapter which summarises the contents of the book in 27 pages under seven headings.

Under "Technology Environment", the "X-terminal", implementing the $\mathrm{X}$-window protocol, is singled out as "a machine that may become of great importance for retrieval systems". I am unaware of any evidence to 
support this notion. The area is highly competitive and there are many contenders. But a cool and realistic view is taken of hypertext databases which have received enormous exposure. "Their widespread implementation is unlikely" says the book. A similar view is taken of natural language, speech processing, and expert intermediary systems "unlikely to become feasible access modes to large text databases because of the huge amounts of domain knowledge needed for their full implementation".

Comments about the "low relative performance of CD-ROM" causing it to remain "as a personal publishing system" seem misplaced in view of the stunning developments in data compression. Incidentally I cannot find any mention of compression in the book. Claude Shannon was academically interested in compression but could hardly have foreseen its implementation as algorithms of lightning speed in real time.

One substantial change is forecast:- "HDTV standards will ensure that electronic media will replace $16 \mathrm{~mm}$ film entirely, and could make inroads into $35 \mathrm{~mm}$ " but (later on page 115) "will not touch larger film formats". Perhaps this book was not the place to single out HDTV as a revolutionary development, because the revolution will be in "entertainment" which is separated from "information" by a fuzzy border. The "movie" industry, the film distribution mechanism, and the continuing existence of the "movies" as we know them will be transformed, if not destroyed by HDTV, but only as the numbers of HDTV receivers reach some critical mass. The instability of current HDTV developments is such that it would be foolish to make any forecasts about when this will be.

With regard to telecoms, the book makes a sober comment, likely to be correct:- "Most of the innovations which will have penetrated to any depth by 2000 should be visible by now". In respect of telecommuting and in spite of numerous statements and articles to the contrary the book rightly says "There may an increase in telecommuting (working at home using a computer connected to the employer's premise) but there is little evidence so far of appreciable growth in this mode of working".

The book puts paid to optimistic ideas about "electronic books" "Most organisations dealing with the general public will still be communicating with them via paper in the year 2000". I wonder what the book might have said had the year been extended to 2020?

The book thinks (in the overview) that "in some areas printed (scientific and technical) journals may disappear because the major product of the area is data and deposit of data in a databank may be accepted as the equivalent of a journal article... The "publish or perish" syndrome may change... publication on CD-ROM with the end users paying for each contribution printed down or downloaded may also lead to the effective demise of the journal structure".

It may sound reasonable that technically-oriented scientists and technologists will take to electronic media, which presumably includes reading from an electronic display of some kind. In its main body the book devotes 7 pages to the electronic journal but manages to avoid saying that all attempts at publishing several different variations of it have ended in abject failure - assuming that success is judged by the desire of a sufficient number of people to contribute to, and read them. 
The reason is that humans are conservative and don't like to see a serious disturbance of well-established customs which more or less ensure that ability is rewarded. The sociology of science has been so well documented that I will not dwell on it - it hinges on established publication practices. See, for example, Jerry Gaston's Originality and competition in science (University of Chicago Press, 1973), Cole and Cole's Social stratification in science (1973) by the same publisher, and, above all, the work of Robert Merton, well covered in Coser's (Ed.) The idea of a social structure: papers in honour of Robert K. Merton (Harcourt Brace Jovanovich. 1975).

Other social matters are covered in some detail. The usual point about the growth of people employed in information work is discussed. In the UK the proportion employed in "information industries" is quoted as being $28.1 \%$ in 1981 , rising to an expected $30.9 \%$ in 1995 , and in "information occupations for the same years $34.8 \%$ rising to $40.9 \%$.

Many statistics are provided for libraries in the UK, and although reading has declined it is considered that despite the growth of broadcasting and video "their impact seems to have been marginal".

In its final section "Recommendations for action" the book concludes that "The lack of a national information policy has been the subject of controversy for many years. What is needed is some overall concern with the information environment at Cabinet level". Other significant issues are the possible introduction of a Freedom on Information Act and the question of the legal deposit of non-paper publication.

There may well be a case for a standing committee on telecoms for the information communities and a strategic planning group to consider the kinds of services that might be carried.

Library and information schools will have to prepare themselves for "the drift away from formal training, alternative routes to qualification, and an influx students from other countries".

Finally the book says "The library and information community is at the mercy of the general economic climate and the marketplace. Most certainly the resources available in the next decade will be limited as they are today... we shall have to shift the emphasis by reducing the level of one service to provide for another or carry through a process of renewal with newer services being offered in place of the old".

\section{A.E.Cawkell}

